\title{
Hospital Visits from Respiratory Diseases of Early and Late Preterm Infants
}

\author{
Sangmi Park, Soo Kyung Nam, Juyoung Lee, and Yong Hoon Jun \\ Department of Pediatrics, Inha University Hospital, Inha University School of Medicine, Incheon, Korea
}

\section{ABSTRACT}

Purpose: We aimed to evaluate the respiratory illness-related hospital visits (out-patient clinics, emergency room, and re-admission) of preterm infants, and compare them according to corrected age and prematurity.

Methods: We reviewed the medical records of preterm infants born at $<37$ weeks of gestation admitted to the neonatal intensive care unit (NICU) at Inha University Hospital between January 2012 and June 2015. Infant follow-up appointments in both neonatology and pulmonology out-patient clinics occurred for at least 2 years after NICU discharge.

Results: The proportion of infants who visited the hospital due to any respiratory illness was as high as $50 \%$ until 12 months of corrected age, and subsequently decreased over time. Hospital admission was significantly higher in early preterm infants ( $<34$ weeks of gestation) compared to late preterm infants ( $\geq 34$ and $<37$ weeks of gestation). The proportion of infants who were re-admitted due to lower respiratory tract illness was significantly higher until 6 months of corrected age compared to the later, and did not differ between early and late preterm infants.

Conclusion: The proportion of hospital visits of preterm infants due to respiratory disease was high until 12 months of corrected age. Most notably, the re-admission proportion from lower respiratory tract illness was high under 6 months in both early and late preterm infants. Preterm infants within this age that are visiting the hospital with respiratory symptoms should be carefully observed and followed up.

Key Words: Preterm infants, Patient readmission, Respiratory tract diseases

서론

통계청 보고에 따르면 지난 10년 동안 임신나이 37주 미만의 미숙아 출생은 2005년 4.8\%에서 2015년 6.9\%로 상승하였다 ${ }^{1)}$. 미숙아들은 출생 후 신생아집중치료실에서 초기 생체활력징후의 안정, 호흡 및 영양보조 후 적절한 입원 기간을 거쳐 퇴원하게 되는데, 퇴원 이후에도 재입원을 하게 되는 경우가 많고 재입원의 주요한 원인은 호흡기계 질환으로 알려져 있다 ${ }^{2,3)}$. 태아의 폐는 만삭 시기에 이르기까지 폐포를 구성하고 있는 세포가 성숙의 과정을 거치게 되는데 이를 채우
Received: 30 April 2018

Revised: 14 August 2018

Accepted: 16 August 2018

Correspondence to: Juyoung Lee

Department of Pediatrics, Inha University Hospital, Inha University School of Medicine, 27 Inhang-ro, Jung-gu, Incheon 22332, Korea

Tel: +82-32-890-3506

Fax: +82-32-890-2844

E-mail: juyounglee@inha.ac.kr

Copyright(c)

By Korean Society of Neonatology.

All right reserved.

This is an Open-Access article distributed under the terms of the Creative Commons Attribution Non-Commercial License (http://creativecommons.org/licenses/ by-nc/4.0), which permits unrestricted non-commercial use, distribution, and reproduction in any medium, provided the original work is properly cited. 
지 못하고 출생하는 미숙아들은 폐 성숙 과정이 충분히 일어나지 못 한 상태로 태어나게 되어 이로 인해 출생 직후의 호흡곤란의 위험이 높으며, 생후 수개월 내지 수년 동안 만삭아에 비해 호흡기 질환의 빈도가 높다 ${ }^{4-6)}$. 신생아 호흡곤란의 고위험으로 알려진 임신나이 34 주 미만의 조기 미숙아뿐만 아니라, 임신나이 34 주 이후의 후기 미 숙아에게서도 유아기의 호흡기 질환의 빈도가 높으며 가장 큰 상관 관계가 있는 시기는 생후 1 년이라 보고되고 있다 ${ }^{7)}$.

현재 국내 신생아집중치료실을 퇴원하는 미숙아들의 생후 수개 월 혹은 수년의 폐 성숙 과정 중 호흡기 질환으로 인한 병원 재방문 에 대한 연속성(serial) 있는 보고는 부족한 상태이다. 이번 연구에서 는 신생아집중치료실에 입원했던 미숙아에서 생후 4 년까지 교정연 령에 따라 호흡기 질환으로 인한 외래, 응급실 방문 및 재입원이 어 떠한 양상을 보이는지 확인하고, 이를 임신나이 34 주 미만으로 출생 한 조기 미숙아와 임신나이 34주 이상으로 출생한 후기 미숙아로 나 누어 비교해 보고자 하였다.

\section{대상 및 방법}

\section{1. 대상}

2012년 1월부터 2015년 6월까지 인하대병원 신생아집중치료실에 입원했던 임신나이 37 주 미만으로 출생한 미숙아 중 최소 2 년 이상 신생아분과와 호흡기분과에서 지속적으로 추적 관찰이 이루어진 환 자들을 대상으로 하였고, 추적 관찰 중 사망하거나 타 병원으로 전원 된 경우, 임상정보가 불완전한 경우, 심장이나 호흡기계에 선천적인 기형이 있는 경우를 제외하였다.

\section{2. 방법}

대상 환자를 임신나이 $33^{+6}$ 주 이하의 조기 미숙아와 임신나이 $34^{+0}-36^{+6}$ 주의 후기 미숙아, 두 군으로 나누어 의무기록을 후향적으 로 검토하였고 사회-인구통계학적 정보는 임신나이, 출생체중, 성 별, 부당 경량아, 형제 유무, 다태아 여부를 조사하였다. 산과적 특 성으로 분만방법, 산모의 나이를 조사하였고, 입원 시 임상관찰 항 목으로 신생아호흡곤란증후군, 24 시간 이상의 인공호흡기 사용, 24
시간 이상의 산소 투여, 기관지폐이형성증 등을 조사하였다. 신생아 호흡곤란증후군은 폐표면활성제를 사용한 경우로 정의하였고, 기 관지폐이형성증은 교정연령 36주에 산소 또는 양압 환기 치료가 필 요한 경우로 정의하였다. 신생아집중치료실에서 퇴원한 이후 호흡 기 증상으로 내원한 외래 및 응급실 방문, 재입원 이력을 전자차트를 통해 수집하였고, 교정연령 48개월까지의 추적 관찰기록을 확인하 였다. 본 연구는 후향적 데이터 분석연구로 연구자의 동의서 취득이 면제되며, 연구의 계획은 사전에 인하대병원 기관생명윤리위원회 의 승인을 받았다.

\section{3. 통계}

통계학적인 분석으로 두 군의 여러 인자를 비교하기 위해 IBM SPSS Statistic version 19.0 (IBM Co., Armonk, NY, USA)을 사용하였 다. 조사된 자료의 값은 빈도(백분율) 또는 중앙값(범위)으로 표기 하였고 각 군 간의 비교는 chi-square test 또는 Fisher's exact를 사용 하였고 $P$ 값이 0.05 미만인 경우를 통계학적으로 의미가 있다고 판정 하였다.

\section{1. 대상 환자군의 분포 및 특징}

2012년 1월부터 2015년 6월까지 인하대병원 신생아집중치료실 에 입원했던 임신나이 37 주 미만의 미숙아는 총 827 명이었으며, 이 들 중 제외 기준을 만족하지 않으며, 최소 2 년 이상 신생아분과와 호 흡기분과에서 지속적으로 추적 관찰이 이루어진 환자는 248명(30\%) 이었다(Figure 1). 이들의 임신나이 중앙값은 34.0주(사분범위, $30.4-35.3$ ), 출생체중의 중앙값은 $1,955 \mathrm{~g}$ (사분범위, $1,480-2,318$ ) 이었다. 이중 남아는 128 명으로 $51.6 \%$ 를 차지하였다. 이를 조기 미 숙아군과 후기 미숙아군으로 나누어 두 군의 특성을 비교한 결과는 Table 1과 같았다. 조기 미숙아군과 후기 미숙아군의 임신나이는 중 앙값이 각각 31.4주(사분범위, 28.9-33.1), 35.3주(사분범위, 34.636.1 ) 였고 출생체중은 중앙값이 각각 $1,580 \mathrm{~g}$ (사분범위, $1,170-$ 1,910 ), $2,300 \mathrm{~g}$ (사분범위, 2,040-2,745)이었다. 두 군에서는 성별,

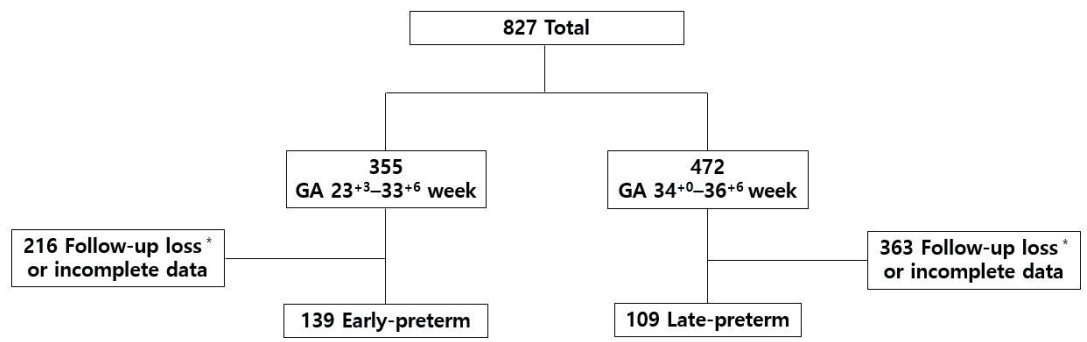

Figure 1. Study participants. Excluded infants were cases with transfer-out, death, follow-up loss, or follow-up duration $<2$ years. Abbreviation: GA, gestational age. 
Table 1. Characteristics of Included Patients

\begin{tabular}{|c|c|c|c|c|}
\hline Characteristic & All included infants $(n=248)$ & Early-preterm infants $(n=139)$ & Late-preterm infants $(n=109)$ & $P$-value \\
\hline Gestational age (wk) & $34.0(30.4-35.3)$ & $31.4(28.9-33.1)$ & $35.3(34.6-36.1)$ & $<0.001$ \\
\hline Birth weight (g) & $1,955(1,480-2,318)$ & $1,580(1,170-1,910)$ & $2,300(2,040-2,745)$ & $<0.001$ \\
\hline Male sex & $128(51.6)$ & $67(48.2)$ & $61(56.0)$ & 0.250 \\
\hline Multiple pregnancy & $49(19.8)$ & $26(18.7)$ & $23(21.1)$ & 0.748 \\
\hline Small for gestational age & $6(2.4)$ & $4(2.9)$ & $2(1.8)$ & 0.698 \\
\hline Vaginal delivery & $112(45.2)$ & $60(43.2)$ & $52(47.7)$ & 0.521 \\
\hline Maternal age (yr) & $33(30-36)$ & $34(31-36)$ & $33(30-36)$ & 0.136 \\
\hline Siblings & $140(56.5)$ & $76(54.7)$ & $64(58.7)$ & 0.606 \\
\hline Respiratory distress syndrome* & $57(23.0)$ & $57(41.0)$ & 0 & $<0.001$ \\
\hline Oxygen treatment, $>24$ hours & $121(48.8)$ & $92(66.2)$ & $29(26.6)$ & $<0.001$ \\
\hline Ventilator care, $>24$ hours & $65(26.2)$ & $56(40.3)$ & $9(8.3)$ & $<0.001$ \\
\hline Bronchopulmonary dysplasia $^{\dagger}$ & $25(10.1)$ & $25(18.0)$ & 0 & $<0.001$ \\
\hline
\end{tabular}

Values are expressed as median (interquartile range) or number (\%).

*Defined as surfactant treatment; ${ }^{\dagger}$ Defined as oxygen therapy or positive pressure ventilation at postmenstrual age 36 weeks.
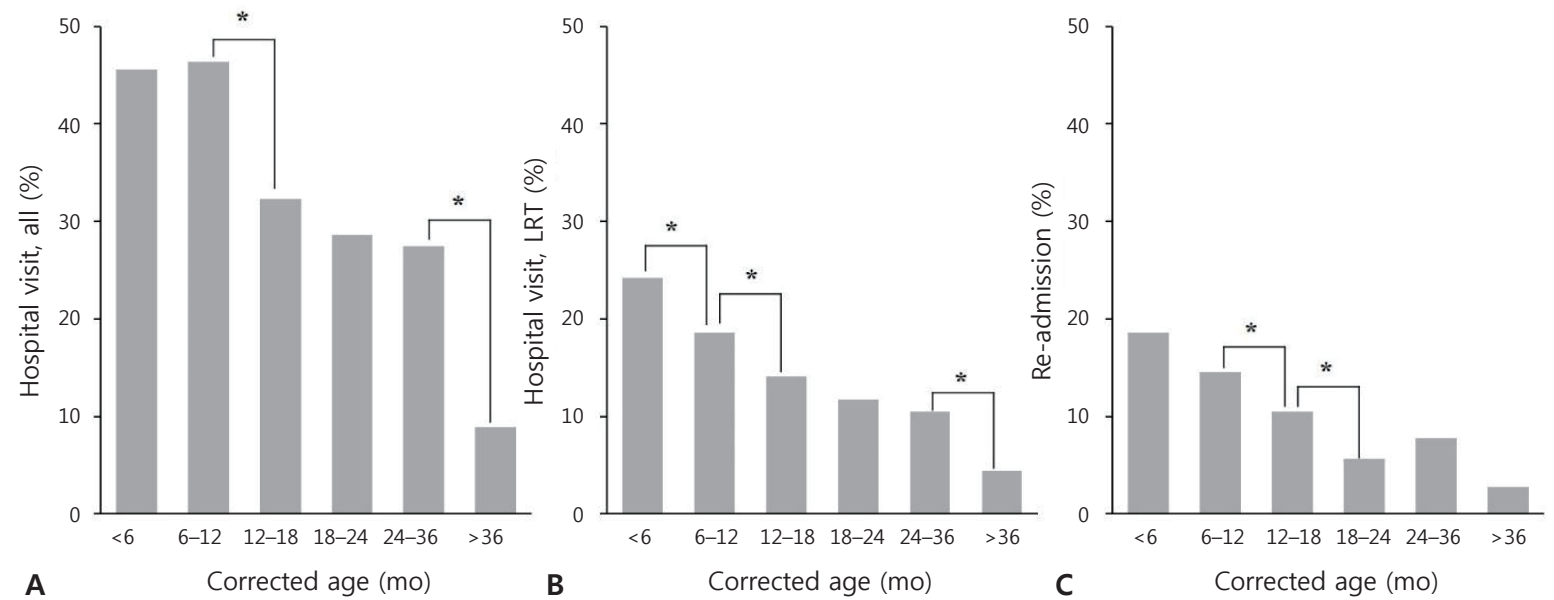

Figure 2. Rate of hospital visits from respiratory diseases according to the corrected age of all preterm infants. (A) All hospital visits include visits on out-patient clinics, emergency rooms, and re-admission due to any respiratory illness: $<6$ months of age, $45.6 \%$; 6 to 12 months of age, $46.4 \% ; 12$ to 18 months of age, $32.3 \%$; 18 to 24 months of age, $28.6 \%$; 24 to 36 months, $27.4 \%$; $>36$ months of age, $12.0 \%$. (B) Hospital visits include visits on out-patient clinics, emergency rooms, and re-admission due to lower respiratory tract (LRT) illness: $<6$ months of age, $24.2 \% ; 6$ to 12 months of age, $18.5 \%$; 12 to 18 months of age, $14.1 \%$; 18 to 24 months of age, $11.7 \%$; 24 to 36 months, $10.5 \%$; $>6$ months of age, $6.0 \%$. (C) Readmission due to LRT illness: $<6$ months of age, $18.5 \%$; 6 to 12 months of age, $14.5 \%$; 12 to 18 months of age, $10.5 \%$; 18 to 24 months of age, $5.7 \%$; 24 to 36 months, $7.8 \%$; $>36$ months of age, $2.7 \% .{ }^{*} P<0.05$.

부당 경량아 및 다태아 여부, 출산방법, 산모나이, 형제 유무 등에서 는 통계학적으로 의미 있는 차이는 없었다. 그러나 신생아호흡곤란 증후군은 조기 미숙아군에서만 발생하여 유의한 차이( $41 \% \mathrm{vs.} 0 \%$, $P<0.001)$ 가 있었고, 24 시간 이상 산소(66.2\% vs. $40.3 \%, P<0.001)$ 및 인공환기요법치료 $(26.6 \% \mathrm{vs} .8 .3 \%, P<0.001)$ 가 필요했던 경우도 조 기 미숙아군에서 유의하게 많이 발생하였다(Table 1).

\section{2. 교정연령에 따른 호흡기 질환으로 인한 병원 방문 비교}

미숙아들이 호흡기 질환으로 외래, 응급실, 재입원으로 병원에 방
문한 빈도를 교정연령에 따라 비교한 결과, 교정연령 6개월 미만에 서는 $45.6 \%$ (113/248), 6개월에서 12개월 사이에는 46.4\% (115/248) 가 병원에 방문하여 교정연령 6개월 전후로는 그 차이가 거의 없었 다. 그러나 교정연령 12 개월이 지나면서 18개월까지는 32.3\% (80/ 248)가 병원에 방문하여 그 빈도가 유의하게 감소하였고, 이후 교정 연령이 증가할수록 병원에 방문하는 빈도가 감소하여 교정연령 36 개월 이후에는 $12.0 \%(22 / 183)$ 만 호흡기 질환으로 병원에 방문하였 다(Figure 2A).

그러나, 병원에 방문한 원인이 하기도 질환인 경우만으로 범위를 


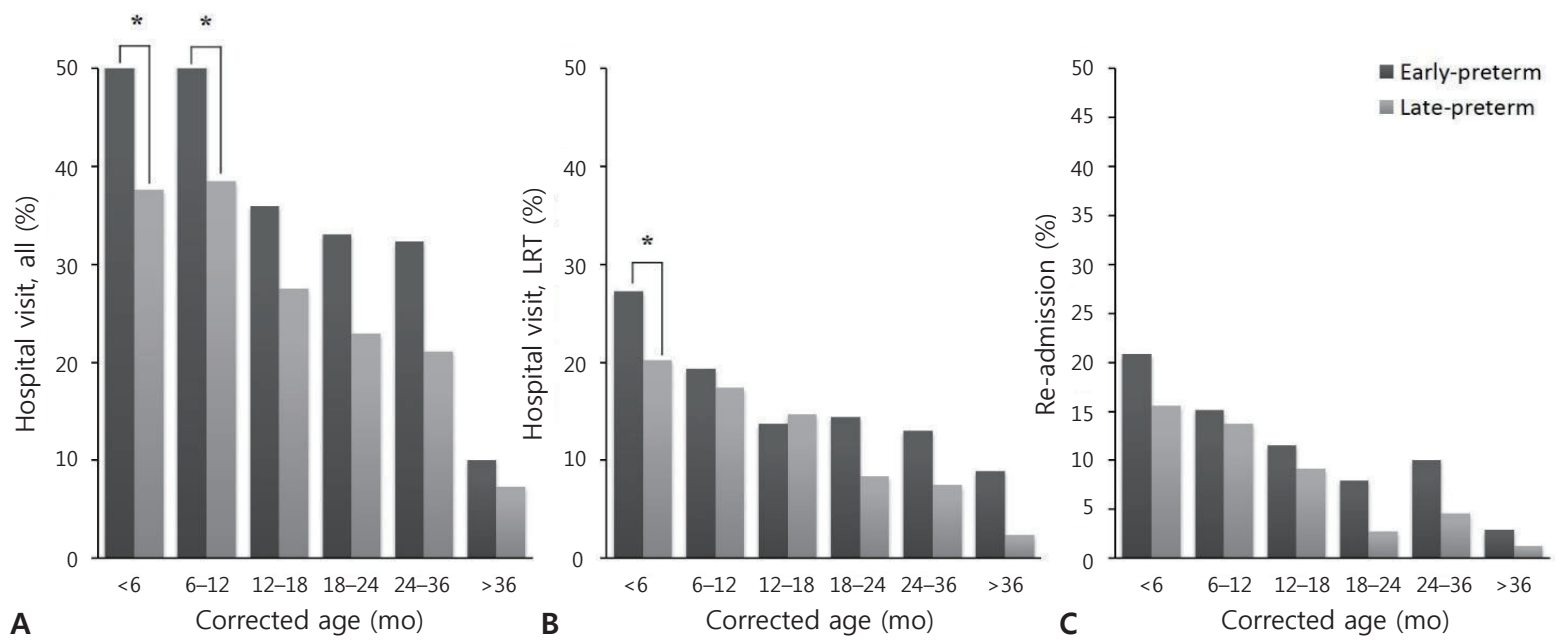

Figure 3. Comparison of early and late preterm infants on hospital visits from respiratory diseases according to the corrected age. (A) All hospital visits include visits on out-patient clinics, emergency rooms, and re-admission due to any respiratory illness: $<6$ months of age, $51.8 \%$ vs. $37.6 \%$; 6 to 12 months of age, $52.5 \%$ vs. $38.5 \%$; 12 to 18 months of age, $36.0 \%$ vs. $27.5 \%$; 18 to 24 months of age, $33.1 \%$ vs. $22.9 \%$; 24 to 36 months, $32.4 \%$ vs. $21.1 \%$; $>36$ months of age, $10.1 \%$ vs. $7.3 \%$. (B) Hospital visits include visits on out-patient clinics, emergency rooms, and re-admission due to lower respiratory tract (LRT) illness: $<6$ months of age, $27.3 \%$ vs. $20.2 \%$; 6 to 12 months of age, $19.4 \%$ vs. $17.4 \%$; 12 to 18 months of age, $13.7 \%$ vs. $14.7 \%$; 18 to 24 months of age, $14.4 \%$ vs. $8.4 \%$; 24 to 36 months, $13.0 \%$ vs. $7.5 \%$; $>36$ months of age, $8.9 \%$ vs. $2.4 \%$. (C) Readmission due to LRT illness: $<6$ months of age, $20.9 \%$ vs. $15.6 \%$; 6 to 12 months of age, $15.1 \%$ vs. $13.8 \% ; 12$ to 18 months of age, $11.5 \%$ vs. $9.2 \%$; 18 to 24 months of age, $7.9 \%$ vs. $2.8 \%$; 24 to 36 months, $10.1 \%$ vs. $4.6 \%$; $>36$ months of age, $2.9 \%$ vs. $1.2 \%$. ${ }^{*} P<0.05$.

좁혔을 때는, 교정연령 6개월 전보다 교정 6-12개월 사이에 유의하 게 감소하였으며(24.2\% [60/248] vs. $18.5 \%$ [46/248], $P=0.021)$, 교정 12 개월 이후에는 더욱 감소하여 교정 $12-18$ 개월에 $14.1 \%(35 / 248)$ 로 감소하였고, 36 개월 이후에는 $6.0 \%(11 / 183)$ 만이 하기도 질환으 로 병원에 방문하였다(Figure 2B).

하기도 질환 중에 질병이 심각한 경우 입원을 하였는데, 교정연 령 6개월 미만에 재입원한 경우는 전체 미숙아의 $18.5 \%$ (46/248)였 으며, 이후 교정연령 12 개월 전후( $14.5 \%$ [36/248] vs. 10.5\% [26/248], $P=0.038), 18$ 개월 전후( $10.5 \%$ [26/248] vs. $5.7 \%[14 / 248], P=0.001)$ 로 유의 있게 감소하였다(Figure $2 \mathrm{C}$ ). 입원한 환자 중 인공환기나 중환 자실 치료를 받은 환자는 없었다.

\section{3. 조기 미숙아와 후기 미숙아의 교정연령에 따른 호흡기 질 환 병원 방문 비교}

대상 환자를 조기 미숙아와 후기 미숙아로 나누어 교정연령에 따 른 병원 방문을 비교해보면, 호흡기 질환으로 외래, 응급실 및 재 입원을 통한 병원 방문은 교정연령 6개월 미만에서 조기 미숙아는 $51.8 \%$ (72/139), 후기 미숙아는 37.6\% (41/109)였고, 교정연령 6-12 개월에서는 조기 미숙아는 52.5\% (73/139), 후기 미숙아는 $38.5 \%$ (42/109)로 두 그룹 모두에서 12개월 미만일 때 병원에 방문한 빈 도가 높았고, 그 차이는 조기 미숙아가 후기 미숙아에 비해 유의하 게 높았다(Figure $3 \mathrm{~A}$ ). 조기 미숙아 중 호흡기 질환에 더 취약하다
고 알려져 있는 임신나이 28주 미만의 초미숙아를 나누어서 살펴 보았을 때, 교정연령 6개월 미만에서는 68.0\% (17/25), 6-12개월에 서는 $60.0 \%$ (15/25)로 초미숙아를 제외한 조기 미숙아에 비해(6개 월: $48.2 \%$ [55/114]; 6-12개월: 50.9\% [58/114]) 병원 방문이 더 많았 고, 12 개월 이후 병원 방문이 감소하기는 하였으나 36 개월 이후에도 $25.0 \%(5 / 20)$ 나 병원에 방문하였다.

하기도 질환으로 인한 병원 방문의 빈도는 전체 호흡기 질환으로 인한 방문과 다르게 교정 6개월 미만에서만 조기 미숙아에서는 27.3 $\%$ (38/139), 후기 미숙아에서는 20.2\% (22/109)로 조기 미숙아가 후 기 미숙아에 비해 유의하게 높은 비율을 보였으며, 이후에는 조기 미 숙아와 후기 미숙아에서 유의한 차이가 없었다(Figure 3B). 재입원 이 필요할 정도의 호흡기 질환은 조기 미숙아와 후기 미숙아, 두 군 모두에서 교정연령에 상관없이 통계학적 유의한 차이를 보이지 않 았다(Figure 3C). 이 역시 조기 미숙아 중 초미숙아를 나누어 살펴보 았을 때, 교정연령 6개월 미만에서 초미숙아는 $24.0 \%$ (6/25), 초미 숙아 제외 조기 미숙아는 20.9\% (29/139), 후기 미숙아는 15.6\% (17/ 109)로 큰 차이를 보이지 않았고 이들의 재입원은 교정연령이 증가 할수록 감소하여 36개월 이상에서는 조기 미숙아는 4.0\% (4/101), 후 기 미숙아는 $1.2 \%(1 / 82)$ 까지 감소하였다. 
고찰

본 연구에서는 미숙아들이 호흡기 질환으로 외래 및 응급실, 재입 원을 통해 병원에 방문하는 비율이 교정연령 12 개월 미만에서 $50 \%$ 에 가까운 정도로 높았고 점차 감소하여 36 개월 이후에는 그 전에 비 해 유의하게 감소한다는 것을 확인하였으며, 호흡기 질환으로 인한 병원 방문이 교정 12 개월까지는 조기 미숙아가 후기 미숙아에 비해 서 더 많다는 것을 확인할 수 있었다. 또한 조기 미숙아 중에서도 임 신나이 28주 미만의 초미숙아인 경우 병원 방문이 다른 미숙아에 비 해 더 많은 것을 확인할 수 있었다. 이는 미숙아에서 생후 1 년간 호 흡기 질환의 이환율이 높고 이후 점차 감소하며 미숙함이 심할수록 호흡기 질환에 취약하다는 이전 보고들과 일치한다 ${ }^{6,89}$. 그러나 하 기도 질환으로 인한 병원 방문은 교정 6개월까지만 조기 미숙아에서 후기 미숙아보다 높은 비율을 보이고 그 이후에는 큰 차이가 없었으 며, 재입원이 필요한 심한 하기도 질환의 비율은 전체 연령에서 조기 미숙아와 후기 미숙아 간 유의한 차이가 없었다.

임신 34주 이후 출생하는 후기 미숙아는 전체 미숙아의 60\%$70 \%$ 가량이 되며, 1999년 이후 꾸준히 늘고 있어 미숙아 관리에 중 요한 이슈가 되고 있다 ${ }^{10)}$. 태아는 출생 전 자궁 내에서 뇌와 폐, 그리 고 다른 기관들의 성장 및 발달이 완성되는 중요한 시기를 거쳐 만삭 이 되어 출생하여 정상적인 신생아기로 이행되어야 하는데 조기 미 숙아뿐만 아니라 후기 미숙아 역시 그 시기를 거치지 못하여 미성숙 한 상태로 출생하게 된다 ${ }^{11-14)}$. 폐의 발달에서도, 폐포는 임신 28-30 주 경부터 형성되기 시작하지만, 만삭이 되어서야 폐포가 완성되고 그 발달은 생후 3-7년까지도 진행되기 때문에 ${ }^{15)}$ 조기 미숙아뿐만 아니라 후기 미숙아 역시 폐포의 발달과정 중 충분한 성숙 전에 출 생하는 것이다. 그로 인해 후기 미숙아들 역시 출생 이후 신생아호 흡곤란증후군, 신생아 일과성 빈호흡, 폐렴, 무호흡 등의 호흡기 질 환으로 신생아집중치료실로 입원하는 빈도가 높고, 특히 제왕 절개 를 통한 분만에 의해서 출생하는 후기 미숙아들에서 이러한 호흡기 계 질환의 발생 위험도가 더 높다고 보고되고 있다 ${ }^{16}$. 미숙아에서 잘 동반되는 자궁 내 성장지연이나 저체중 출생이 폐 기능 손상에 영향 을 주게 되고, 산모의 조기 진통의 중요한 원인이 되는 융모양막염도 폐포의 성장 및 발달을 억제하여 그저 숫자로써의 조산보다 더욱 호 흡기 질환으로의 이행에 영향을 주며, 염증 반응은 폐 계면활성제의 불활성화를 유발하여 호흡곤란의 위험을 증가시키는 것으로 알려져 있다 ${ }^{17-20)}$. 이러한 이유로 출생 직후에 호흡 곤란이 없었던 미숙아들 도 손상되거나 발달이 저해된 폐를 갖게 되고 이후의 폐 성장 및 발 달에도 영향을 받아 생후 3-5세까지 호흡기 감염에 취약하며, 일부 는 성인이 되어서까지도 폐 기능이 정상에 이르지 못하여 만성적인 폐 질환으로 이어질 수 있다 ${ }^{21-25}$ 고 알려져 있어 미숙아들에 있어서 장기적인 호흡기 관리가 필요하다. 본 연구의 결과에서도 보듯이, 후기 미숙아에서 심한 하기도 질환이 발생할 가능성이 조기 미숙아
에 비해 낮지 않아 폐 성숙이 충분히 일어나는 시점까지는 이들의 감 시 및 추적 관찰이 중요할 것으로 생각된다.

이는 국내의 Choi 등 ${ }^{26}$ 의 연구에서도 확인 할 수 있는 바, 후기 미 숙아가 만삭아에 비해 호흡기 관련 질환으로 입원할 위험이 1.69배 높았으며 호흡기 질환으로 인한 입원횟수에서도 같은 결과를 보였 다. Shin 등 ${ }^{3)}$ 의 연구에서도 후기 미숙아의 재입원율은 $18.9 \%$ 로 중기 미숙아의 $21.9 \%$ 에 비해 낮지만, 만삭아 $16.7 \%$ 에 비해 유의하게 높 았다. 본 연구에서는 만삭아와는 비교하지 못하였으나 이전 연구 결 과들에서 조기 미숙아뿐만 아니라 후기 미숙아의 재입원도 만삭아 에 비해 많은 것은 확인 할 수 있었다. 그러나 이전 연구와는 다르게, 본 연구 결과에서 조기 및 후기 미숙아의 호흡기 질환으로 인한 재입 원은 교정연령 전체에서 유의한 차이가 없었고, 후기 미숙아도 입원 이 필요한 하기도 질환이 조기 미숙아와 비슷한 정도의 비율로 발생 할 수 있다는 것을 확인 할 수 있었다. 다행히도, 두 군 모두에서 연 령이 증가함에 따라 호흡기 질환으로 인한 병원 방문이 감소하였고, 이는 폐포 발달 및 재형성 ${ }^{15}$ 의 결과라고 유추할 수 있다.

이번 연구는 단일기관의 후향적 연구라는 점과 본원 신생아집중 치료실 퇴원 이후 24 개월 이상 추적 관찰하고 있는 비율이 $30 \%$ 정도 로 그리 높지 않았던 점, 그리고 만삭아와의 비교가 없었다는 제한점 이 있으며, 또한 병원 방문의 비율이 가정환경이나 부모의 경제적 여 건, 사보험 유무 등에 의해 영향을 받았을 것이며, 호흡기 질환은 손 위 형제의 유무나 그들의 어린이집 이용에 의해 그 빈도의 차이를 보 일 수 있으므로 균일한 집단의 결론이라고 단정 지을 수는 없다. 그 러나 본 연구를 진행한 병원이 인천의 큰 거점병원이며, 호흡기분과 의료진이 2 명 이상으로 일주일 내내 호흡기 질환의 외래 진료가 가 능하며 신생아분과에서 24 개월 이상 꾸준히 추적 관찰했던 환아들 을 대상으로 한 것이고 이를 연속성 있게 평가했다는 것이 큰 의미가 있다고 하겠다. 추후 전국 데이터나 지역 전체의 $1,2,3$ 차 의료기관 의 데이터를 이용한 대규모연구가 이루어진다면, 좀 더 명확한 결론 을 도출해 낼 수 있을 것으로 기대된다.

결론적으로, 조기 및 후기 미숙아들은 호흡기 질환으로 인한 병원 방문의 빈도가 12 개월 이전에 특히 높으며, 특히 6개월 미만에서는 하기도 질환의 이환율이 높다. 따라서 이들의 호흡기 증상에 대한 면밀한 관찰과 추적 관찰이 필요하며, 전체 호흡기 질환의 이환은 조 기 미숙아에서 후기 미숙아보다 빈번하였지만, 입원을 요하는 심한 하기도 질환은 조기 미숙아와 후기 미숙아에서 큰 차이가 없었다는 것을 염두 해야 할 것으로 생각된다.

\section{감사의 글}

이 논문은 인하대병원의 지원에 의하여 연구되었습니다. 


\section{REFERENCES}

1. Korean Statistical Information Service. 2015 Population and Housing Census [Internet]. Daejeon: Korean Statistical Information Service; 2015 [cited 2018 Aug 16]. Available from: http:// kosis.kr/statisticsList/statisticsList_01List.jsp?vwcd=MT_ ZTITLE \& parented=A.

2. Underwood MA, Danielsen B, Gilbert WM. Cost, causes and rates of rehospitalization of preterm infants. J Perinatol 2007;27:614-9.

3. Shin JS, Kim YB, Lee YH, Shim GH, Chey MJ. Comparisons of clinical characteristics affecting readmission between late preterm infants and moderate preterm infants or full-term infants. Neonatal Med 2016;23:211-7.

4. Kotecha S. Lung growth for beginners. Paediatr Respir Rev 2000;1:308-13.

5. Colin AA, McEvoy C, Castile RG. Respiratory morbidity and lung function in preterm infants of 32 to 36 weeks' gestational age. Pediatrics 2010;126:115-28.

6. Vrijlandt EJ, Kerstjens JM, Duiverman EJ, Bos AF, Reijneveld SA. Moderately preterm children have more respiratory problems during their first 5 years of life than children born full term. Am J Respir Crit Care Med 2013;187:1234-40.

7. Slimings C, Einarsdóttir K, Srinivasjois R, Leonard H. Hospital admissions and gestational age at birth: 18 years of follow up in Western Australia. Paediatr Perinat Epidemiol 2014;28:536-44.

8. Lemons JA, Bauer CR, Oh W, Korones SB, Papile LA, Stoll BJ, et al. Very low birth weight outcomes of the National Institute of Child health and human development neonatal research network, January 1995 through December 1996. NICHD Neonatal Research Network. Pediatrics 2001;107:E1.

9. Holman RC, Shay DK, Curns AT, Lingappa JR, Anderson LJ. Risk factors for bronchiolitis-associated deaths among infants in the United States. Pediatr Infect Dis J 2003;22:483-90.

10. Martin JA, Kirmeyer S, Osterman M, Shepherd RA. Born a bit too early: recent trends in late preterm births. NCHS Data Brief 2009;24:1-8

11. Na JY, Park N, Kim ES, Lee HJ, Shim GH, Lee JA, et al. Shortterm clinical outcomes of late preterm infants. Korean J Pediatr 2009;52:303-9.

12. Shapiro-Mendoza CK, Tomashek KM, Kotelchuck M, Barfield W, Weiss J, Evans S. Risk factors for neonatal morbidity and mortality among "healthy," late preterm newborns. Semin Peri- natol 2006;30:54-60.

13. Bulut C, Gursoy T, Ovali F. Short-term outcomes and mortality of late preterm infants. Balkan Med J 2016;33:198-203.

14. Haroon A, Ali SR, Ahmed S, Maheen H. Short-term neonatal outcome in late preterm vs. term infants. J Coll Physicians Surg Pak 2014;24:34-8.

15. Warburton D, Schwarz M, Tefft D, Flores-Delgado G, Anderson $\mathrm{KD}$, Cardoso WV. The molecular basis of lung morphogenesis. Mech Dev 2000;92:55-81.

16. Yoder BA, Gordon MC, Barth WH Jr. Late-preterm birth: does the changing obstetric paradigm alter the epidemiology of respiratory complications? Obstet Gynecol 2008;111:814-22.

17. Pike K, Jane Pillow J, Lucas JS. Long term respiratory consequences of intrauterine growth restriction. Semin Fetal Neonatal Med 2012;17:92-8.

18. Khashu M, Narayanan M, Bhargava S, Osiovich H. Perinatal outcomes associated with preterm birth at 33 to 36 weeks' gestation: a population-based cohort study. Pediatrics 2009;123:10913.

19. Dietz PM, England LJ, Shapiro-Mendoza CK, Tong VT, Farr SL, Callaghan WM. Infant morbidity and mortality attributable to prenatal smoking in the U.S. Am J Prev Med 2010;39:45-52.

20. Speer CP. Neonatal respiratory distress syndrome: an inflammatory disease? Neonatology 2011;99:316-9.

21. Gunville CF, Sontag MK, Stratton KA, Ranade DJ, Abman SH, Mourani PM. Scope and impact of early and late preterm infants admitted to the PICU with respiratory illness. J Pediatr 2010;157:209-14.

22. Weiss ST, Ware JH. Overview of issues in the longitudinal analysis of respiratory data. Am J Respir Crit Care Med 1996; 154(6 Pt 2):S208-11.

23. Gappa M, Stocks J, Merkus P. Lung growth and development after preterm birth: further evidence. Am J Respir Crit Care Med 2003;168:399.

24. Greenough A. Late respiratory outcomes after preterm birth. Early Hum Dev 2007;83:785-8.

25. Stocks J, Coates A, Bush A. Lung function in infants and young children with chronic lung disease of infancy: the next steps? Pediatr Pulmonol 2007;42:3-9.

26. Choi S, Kim S, Oh J, Lee N, Kim S, Kim M, et al. The respiratory morbidities in late-preterm infants compared with the earlypreterm and term infants throughout the first year of life. J Korean Soc Neonatol 2012;19:245-52. 